\title{
The effects of Alisol B 23-acetate in hepatocellular carcinoma via inducing cell apoptosis and inhibiting cell migration and invasion
}

\author{
Ling $\mathrm{Li}^{1}$, Jingjun Cheng ${ }^{2}$, Dedong Zhu ${ }^{1}$, Xiaojun Shi ${ }^{1}$, Yongning $\mathrm{Wei}^{1}$, Sihan $\mathrm{Chen}^{1}$, Zhe Wang ${ }^{1}$ \\ and Denggao Yuan ${ }^{1}$ \\ ${ }^{1}$ Department of Liver Oncology, HwaMei Hospital, University of Chinese Academy of Sciences, Jiangbei District, Ningbo, \\ Zhejiang, China \\ ${ }^{2}$ Department of Internal Medicine, Huangjiahu Hospital Affiliated to Hubei University of Traditional Chinese medicine, \\ Hongshan District, Wuhan, Hubei, China
}

\begin{abstract}
Alisol B 23-acetate (AB23A) is a natural triterpenoid isolated from Chinese herbal medicine and has a variety of biological functions, especially anti-cancer effects. However, the effects and mechanisms of AB23A in hepatocellular carcinoma (HCC) remain unclear. Cell viability, invasion and migration were measured by MTT, Transwell and wound healing assays, respectively. To detect cell cycle and apoptosis, a flow cytometry assay was used. Tumor xenograft experiment was performed to measure tumor growth. The enzymatic assay was used to determine the activity of matrix metalloproteinase (MMP)-2 and -9. Furthermore, the mRNA and protein levels of Bcl-2, Bax, Caspase-3/-9, MMP-2/-9 and phosphatidylinositol 3-kinase (PI3K)/protein kinase B (Akt) were detected by RT-PCR and Western blotting assays. AB23A suppressed cell viability in a concentration-dependent manner, blocked cell cycle, and induced apoptosis via up-regulating Bax, Caspase-3 and Caspase-9, and down-regulating Bcl-2 in HCC cells both in vitro and in vivo. In addition, AB23A inhibited cell invasion and migration through down-regulating MMP-2/-9 activities. The effects of AB23A might be associated with the PI3K/Akt signaling pathway in HCC cells. Taken together, the present data demonstrated that AB23A might play a role in suppressing the progression of $\mathrm{HCC}$, revealing the value of AB23A for hepatocellular carcinoma treatment in clinic.
\end{abstract}

Key words: Alisol B 23-acetate - Hepatocellular carcinoma - Cell viability - Cell invasion - Cell apoptosis

\section{Introduction}

Hepatocellular carcinoma (HCC) is a general malignant tumor around the world and one of the major tumor types that causes cancer-related death worldwide (Jemal et al. 2011; Torre et al.2015). At present, the clinical methods for treating

Electronic supplementary material. The online version of this article (doi: 10.4149/gpb_2020005) contains supplementary material, which is available to authorized users.

Correspondence to: Jingjun Cheng, Department of Internal Medicine, Huangjiahu Hospital Affiliated to Hubei University of Traditional Chinese Medicine, No. 1 West Huangjiahu Road, Hongshan District, Wuhan, Hubei, 430070, China

E-mail: chengjjw2018@126.com
HCC are mainly surgical resection and chemotherapy liver transplantation (Best et al. 2017), which are used for the early-stage of HCC. Since the prognosis remains poor in HCC (Wang 2013), it is necessary to develop more novel and effective compounds for potential clinical treatment in patients with HCC.

With accumulating researches in plants, anti-cancer compounds extracted from herbal plants have received more and more attention. Owing to its multi-level, multitarget, and synergistic anti-hepatoma effects, traditional Chinese medicine has become an important choice for HCC treatment ( $\mathrm{Hu}$ et al. 2013). Alisol B 23-acetate (AB23A) is used in a traditional Chinese herbal medicine as a protostane-type triterpenoid isolated from Alismatis Rhizoma (Jin et al. 2012; Wu et al. 2018), with a molecular formula 
of $\mathrm{C} 32 \mathrm{H} 50 \mathrm{O} 5$ (Fig. 1A) and molecular weight of 514.74 $\mathrm{g} / \mathrm{mol}$. It is commonly used to treat different diseases, including cancer and induced autophagy-dependent cell death through the accumulation of intracellular ROS and subsequent activation of JNK signaling pathway in human colon cancer (Zhao et al. 2017). In human renal proximal tubular cells, AB23A-induced cell apoptosis is mediated by autophagy and nephrotoxicity via $\mathrm{PI} 3 \mathrm{~K} / \mathrm{AKT} / \mathrm{mTOR}$ signaling pathway (Wang et al. 2017). Therefore, more and more attention has been paid to AB23A because of its potential anti-cancer effect and the research value in the treatment of human cancer.

In the current study, we examined the anti-cancer effects of AB23A in HCC cell (SK-HEP-1) and discussed the

$\overline{\mathbf{A}}$

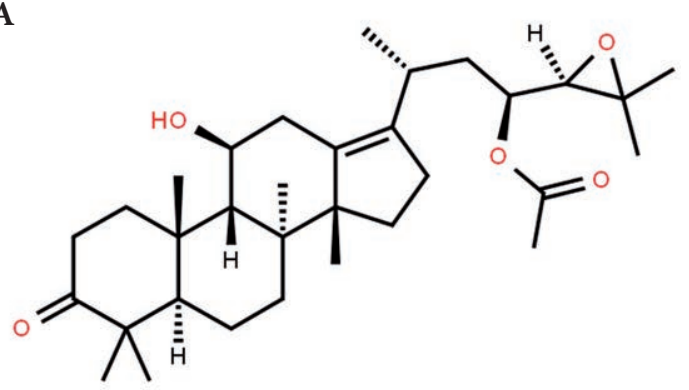

B

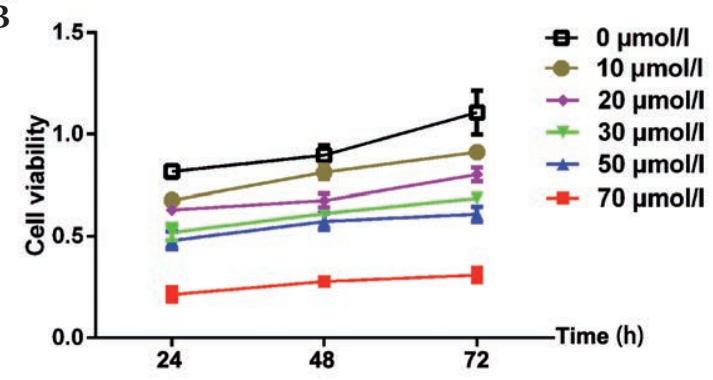

C

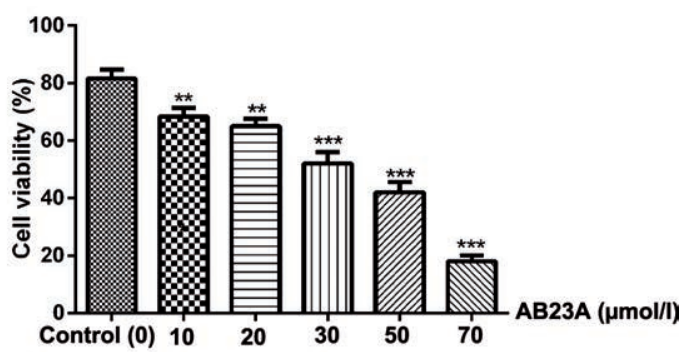

Figure 1. Effects of AB23A on cell growth in SK-HEP-1 cells. A. Chemical structure of AB23A. B. The cell viability of SK-HEP-1 cells treated with various concentrations of AB23A $(10,20,30,50$ and $70 \mu \mathrm{mol} / \mathrm{l}$ ) for 24,48 and $72 \mathrm{~h}$ was determined by MTT assay. C. Quantification of cell viability after 24 -h treatment with various concentrations of AB23A. The cell viability reached about $50 \%$ when SK-HEP-1 cells were exposed to $30 \mu \mathrm{mol} / \mathrm{l} \mathrm{AB} 23 \mathrm{~A}$ for $24 \mathrm{~h}$. Data are mean \pm SD of three experiments. ${ }^{* *} p<0.01$ and ${ }^{* * *} p<$ 0.001 versus Control. molecular mechanism underlying it. First, AB23A inhibited the proliferation of SK-HEP-1 cells in a concentrationdependent manner. Secondly, AB23A up-regulated the expression of Bax, Caspase- 3 and Caspase- 9 and downregulated the protein expression of Bcl-2 in HCC cells to induce cell cycle G1 arrest and cell apoptosis. In addition, AB23A suppressed the invasion and migration of HCC cells by MMP-2 and MMP-9 proteins. Furthermore, AB23A downregulated the PI3K/Akt signaling pathway in HCC to inhibit cell proliferation, invasion and migration and induced cell apoptosis.

\section{Materials and Methods}

\section{Chemical reagents}

AB23A was obtained from National Institutes for Food with a purity of $\geq 98 \%$. AB23A were dissolved in dimethyl sulfoxide (DMSO), and diluted to appropriate concentrations $(10,20,30,50$ and $70 \mu \mathrm{mol} / \mathrm{l})$ with culture medium. The final concentration of DMSO in the culture medium did not exceed $0.1 \%$.

\section{Cell culture}

The human hepatoma cells (SK-HEP-1 cells) were purchased from the Cell Bank of the Chinese Academy of Sciences Committee Type Culture Collection (Shanghai, China). The cells were cultured in DMEM supplemented with 10\% fetal bovine serum (FBS; HyClone), $100 \mathrm{U} / \mathrm{ml}$ penicillin and $100 \mathrm{U} / \mathrm{ml}$ streptomycin. All cells were maintained in the humidified incubator with $5 \% \mathrm{CO}_{2}$ at $37^{\circ} \mathrm{C}$.

\section{MTT assay}

SK-Hep-1 cells were seeded in 96-well plates. The cells were treated with various concentrations of $\mathrm{AB} 23 \mathrm{~A}(10,20,30$, 50 and $70 \mu \mathrm{mol} / \mathrm{l}$ ) for 24,48 and $72 \mathrm{~h}$. Control cell cultures were treated with DMSO. Then, MTT solution (Sigma) was added to each well for $4 \mathrm{~h}$ to form purple crystal formazan. Next, $100 \mu \mathrm{l}$ of DMSO was added and incubated for $10 \mathrm{~min}$ for micro vibration after removing the medium. Absorbance (A) values were measured at $570 \mathrm{~nm}$ in a microplate reader (Bio-Rad Laboratories, Inc., Hercules, CA, USA). The cell viability $=(\mathrm{A}$ of study group $/ \mathrm{A}$ of control group $)$ $\times 100 \%$.

\section{Observation of cell morphology}

SK-HEP-1 cells were seeded into culture bottles. The cells were treated with $30 \mu \mathrm{mol} / \mathrm{l} \mathrm{AB} 23 \mathrm{~A}$ for different times $(12,24,48$ and $72 \mathrm{~h})$. Then the cell morphology was ob- 
served with an inverted microscope at 12, 24, 48 and $72 \mathrm{~h}$, respectively.

\section{Cell cycle analysis}

SK-HEP-1 cells were treated with AB23A (30 $\mu \mathrm{mol} / \mathrm{l})$ for different times $(12,24,48$ and $72 \mathrm{~h}$ ), fixed with $75 \%$ cold ethanol and stored at $4^{\circ} \mathrm{C}$ overnight. The cells were then washed three times with ice-cold PBS and incubated with propidium iodide (PI, $50 \mu \mathrm{g} / \mathrm{ml}$ ) (Sigma-Aldrich) containing $100 \mu \mathrm{g} / \mathrm{ml}$ RNAse-A solution (Invitrogen) and $0.1 \%$ Triton $\mathrm{X}-100$ (Sigma-Aldrich) for $30 \mathrm{~min}$ in the dark at $37^{\circ} \mathrm{C}$. The cell cycle distributions of SK-HEP-1 cells were measured by a FACSCAN flow cytometry (BD Biosciences).

\section{Cell apoptosis assay}

Quantification of apoptotic cells was conducted using a flow cytometry. In short, SK-HEP-1 cells were treated with AB23A (30 $\mu \mathrm{mol} / \mathrm{l})$ for different times $(12,24,48$ and $72 \mathrm{~h}$ ), then washed with PBS and re-suspended in the binding buffer. Subsequently, the cells were incubated with the AnnexinV-FITC and PI mixture for $15 \mathrm{~min}$ at room temperature in the dark, and then binding buffer was added to each tube. The data were analyzed by a flow cytometer with CellQuest software (BD Biosciences).

\section{Transwell assay}

A 24-well Transwell assay was performed to assess cell invasion potential of SK-HEP-1 cells. After being treated with AB23A $(30 \mu \mathrm{mol} / \mathrm{l})$ or control medium for $24 \mathrm{~h}$, cells in serum-free medium were seeded onto the upper chamber with a Matrigel-coated Transwell, and DMEM containing $10 \%$ FBS was deposited into the lower chamber as a chemoattractant. After $24 \mathrm{~h}$ of incubation, the cells remaining on the upper surface of the membrane were scraped off, and the cells on the lower chamber were stained with $0.5 \%$ crystal violet (Sigma). The invasion activity was assessed by counting the number of cells under a microscope (magnification $\times 200)$.

\section{Wound healing assay}

The migration ability was assessed using a wound healing assay. After treating SK-HEP-1 cells with AB23A (30 $\mu \mathrm{mol} / \mathrm{l})$ or control medium for $24 \mathrm{~h}$, the cells were seeded in 6-well plates and cultured when they reached $70-80 \%$ confluence. Subsequently, a wound was scraped with a $100 \mathrm{ml}$ pipette tip and cells were incubated for $24 \mathrm{~h}$. Three randomly images (magnification $\times 200$ ) were then photographed to calculate the related width (\%) of wound healing compared with that at $0 \mathrm{~h}$.

\section{Enzyme assay}

After treating SK-HEP-1 cells with AB23A (30 $\mu \mathrm{mol} / \mathrm{l})$ or control medium for $24 \mathrm{~h}$, the cells were then washed with icecold PBS. The activities of MMP2 and MMP9 were measured using the corresponding enzyme assay kit according to the manufacturer's instructions.

\section{Quantitative real-time PCR assay}

Total RNA was isolated from the cells using TRIzol Reagent according to the manufacturer's instructions. The relative mRNA expression levels of Bax, Bcl-2, Caspase-3, Caspase-9, MMP9, MMP2, PI3K and AKT in SK-HEP-1 cells were detected using a real-time PCR assay. The gene expressions of the detected genes were normalized to the endogenous reference GAPDH. Further, the relative gene expression level was calculated using the formula $2^{-\Delta \Delta \mathrm{Ct}}$ methods.

\section{Tumor xenograft experiment}

After treating SK-HEP-1 cells with AB23A (30 $\mu \mathrm{mol} / \mathrm{l})$ or control medium for $24 \mathrm{~h}$, cells were washed with 100 $\mu \mathrm{l}$ PBS and diluted in $200 \mathrm{ml}$ of Matrigel. BALB/c nude mice (4-6 weeks of age, weight: $18-22 \mathrm{~g}$ ) purchased from the Shanghai Laboratory Animal Research Centre (Shanghai, China) were inoculated with tumor cell suspension subcutaneously $\left(2 \times 10^{6}\right.$ cells/mouse $)$. Then, tumor volume and weight were measured and analyzed by a Vernier caliper after 1, 5, 10, 15 and 20 days. Mice were sacrificed 20 days after tumour xenografting. Subsequently, the expression of protein factors in the tumor tissue was detected by Western blot.

\section{Western blot assay}

After treating SK-HEP-1 cells with AB23A (30 $\mu \mathrm{mol} / \mathrm{l})$ or control medium for $24 \mathrm{~h}$, cells and tumor tissues were collected with ice-cold PBS and then lysed using radio immune precipitation assay (RIPA) lysis buffer (Beyotime Institute of Biotechnology). The protein concentration was quantified using a BCA protein assay (Beyotime Institute of Biotechnology). Afterwards, the protein samples were separated by $12 \%$ SDS-PAGE and then transferred onto polyvinylidene difluoride (PVDF) membranes (Beyotime Institute of Biotechnology). After being blocked with 5\% non-fat milk in TPBS at room temperature for $2 \mathrm{~h}$, the membranes were incubated overnight at $4^{\circ} \mathrm{C}$ with specific primary antibodies, rabbit anti-Bax (1:2000), rabbit antiBcl-2 (1:1000), rabbit anit-Caspase-3 (1:1500), rabbit antiCaspase-9 (1:1500), rabbit anti-MMP9 (1:2000), rabbit antiMMP2 (1:1000), rabbit anti-AKT (1:500), rabbit anti-PI3K 
(1:1000), and rabbit anti-GAPDH antibodies (1:3000), which were all purchased from Abcam company. Subsequently, membranes were incubated with the corresponding secondary antibody (Santa Cruz Biotechnology) for $1 \mathrm{~h}$ at room temperature. Moreover, the signals were detected with an enhanced chemiluminescence (ECL) method (Beyotime Institute of Biotechnology). The data were quantified using Image J software (National Institutes of Health, Bethesda, MD, USA).

\section{Statistical analysis}

Statistical analyses were performed using GraphPad Prism 6.0 (GraphPad Software, Inc., La Jolla, CA, USA). All data are presented as the mean \pm standard deviation (SD). Statistical differences were determined by a Student's $t$-test or one-way ANOVA with Dunnett's multiple comparison post hoc test. A $p$ value $<0.05$ was considered to indicate a statistically significant difference.

\section{Results}

\section{AB23A suppressed the proliferation of HCC cells}

To assess the cell cytotoxicity of AB23A on SK-HEP-1 cells treated with various concentrations $(10,20,30,50$ and $70 \mu \mathrm{mol} / \mathrm{l}$ ) for 24,48 and $72 \mathrm{~h}$, an MTT assay was performed to determine cell viability of SK-HEP-1 cells. As shown in Figure 1B, AB23A significantly inhibited cell viability in a dose manner, and particularly AB23A treatment $(30 \mu \mathrm{mol} / \mathrm{l})$ for $24 \mathrm{~h}$ had showed obvious cytotoxicity on SK-HEP-1 cells (Fig. 1C). These findings suggested that the most appropriate concentration of $\mathrm{AB} 23 \mathrm{~A}$ for subsequent studies in SK-HEP-1 cells was $30 \mu \mathrm{mol} / \mathrm{l}$.

To further investigate the mechanism by which AB23A suppressed cell viability, the cell morphology was observed under an inverted microscope after being treated with $30 \mu \mathrm{mol} / \mathrm{l} \mathrm{AB} 23 \mathrm{~A}$ at $12,24,48$ and $72 \mathrm{~h}$, respectively. As shown in Figure 2, SK-HEP-1 cells in the control group were oval with intact cell nuclear membrane. When

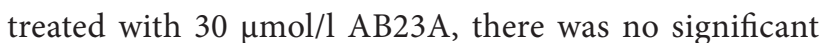
difference in cell morphology between $12 \mathrm{~h}$ and $24 \mathrm{~h}$. At the same time, the cell heterochromatin coagulated in the cell nucleus and it was half-moon shaped near the nuclear membrane at $48 \mathrm{~h}$. As the treatment time of AB23A was prolonged, the cell nuclear membrane gradually dissolved after $72 \mathrm{~h}$ in SK-HEP-1 cells. Additionally, cells presented that the heterochromatin in the nucleus was broken into mass in the cytoplasm, and the membrane was covered, with the apoptotic body formed. Therefore, AB23A inhibits the growth of HCC cells.

\section{AB23A blocked cell cycle and induced cell apoptosis of SK-HEP-1 cells}

Apoptosis is a key anti-proliferative mechanism underlying the anti-tumor drugs commonly used in many tumors. First, we assessed the effect of AB23A on cell apoptosis of SK-HEP-1 cells by a flow cytometry assay. The present

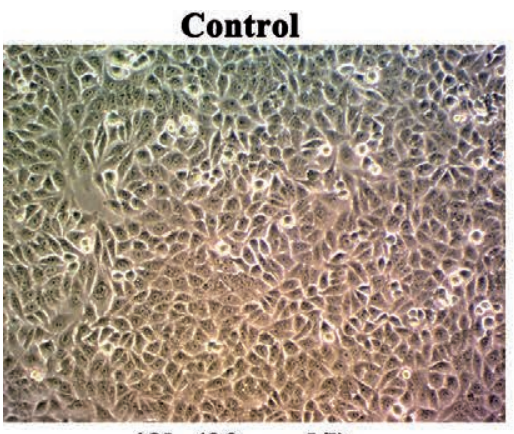

$48 \mathrm{~h}(30 \mu \mathrm{mol} / \mathrm{l})$

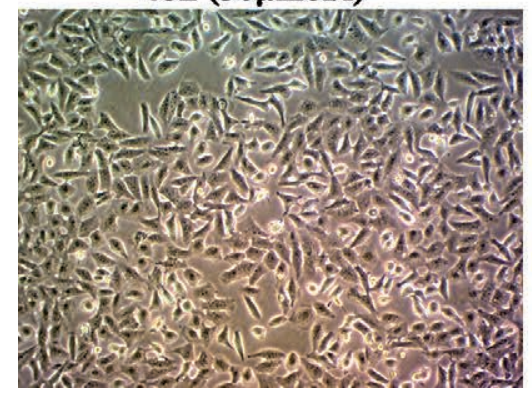

$12 \mathrm{~h}(30 \mu \mathrm{mol} / \mathrm{l})$

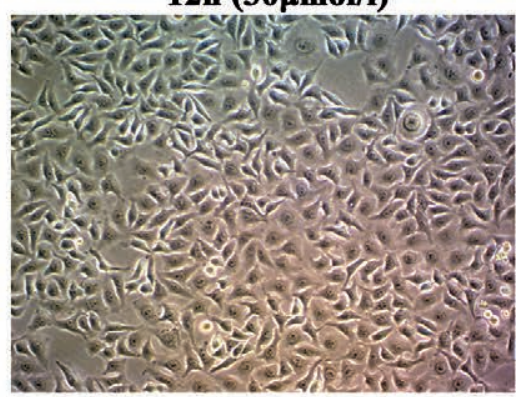

$72 \mathrm{~h}(30 \mu \mathrm{mol} / \mathrm{l})$

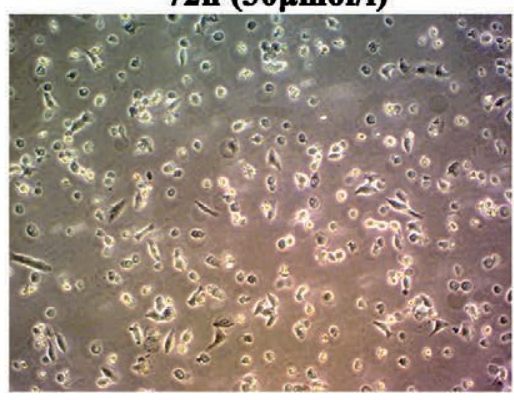

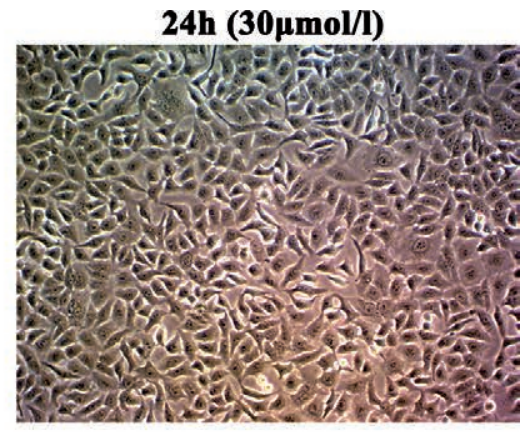

Figure 2. The cell morphology observed by inverted microscope. Representative images of the morphology of SK-HEP-1 cells at different time points (12, 24, 48 and $72 \mathrm{~h}$ ) after AB23A (30 $\mu \mathrm{mol} / \mathrm{l})$ treatment. 
results showed that an increased apoptosis was observed in SK-HEP-1 cells after being treated with $30 \mu \mathrm{mol} / \mathrm{l}$ AB23A with time dependence (12, 24, 48 and $72 \mathrm{~h}$ ) (Fig. 3, at 12 and $24 \mathrm{~h}, p<0.01$; at 48 and $72 \mathrm{~h}, p<0.001)$.

Interfering with cell cycle progression is also a feature of many anticancer drugs. Results from flow cytometry assay showed that when the treatment with AB23A was conducted for different times (12, 24, 48 and $72 \mathrm{~h}$ ), the number of apoptotic cells increased in the $S$ phase and the cell cycle was blocked at G0/G1 phase in a time-dependent manner (Fig. 4, at $12 \mathrm{~h}, p<0.05$; at $24 \mathrm{~h}, p<0.01$; at 48 and $72 \mathrm{~h}, p<0.001)$.

\section{AB23A inhibited the invasion and migration of SK-HEP-1 cells}

Cell migration and invasion play critical roles in the multistep process of cancer cell metastasis. Therefore, we examined the effect of $\mathrm{AB} 23 \mathrm{~A}$ on cell invasion and migration using Transwell assay and scratch wound healing assays. After treatment with $30 \mu \mathrm{mol} / \mathrm{l}$ for $24 \mathrm{~h}, \mathrm{AB} 23 \mathrm{~A}$ inhibited the invasion and migration rate of SK-HEP-1 cells (Fig. 5A and $\mathrm{B}$, both $p<0.01)$.
$A B 23 A$ regulated the expression of $M M P-2, M M P-9$, Caspase-3, Caspase-9, Bax, Bcl-2, PI3K/Akt signaling pathway in SK-HEP-1 cells

To further investigate the mechanism by which $30 \mu \mathrm{mol} / 1$ AB23A inhibited cell invasion and migration, the levels of related proteins MMP-2 and MMP-9 were examined. As shown in Figure 5C and 5D, the results showed that AB23A inhibited the activity of MMP-2 $(p<0.05)$ and MMP-9 $(p<$ $0.01)$ compared with the control group using an enzyme assay. Next, AB23A inhibited the mRNA levels of MMP-2 and MMP-9 (Fig. 6A, $p<0.05$ ) compared with the control group using RT-PCR, and the result of Western blotting assay indicated that $\mathrm{AB} 23 \mathrm{~A}$ inhibited the protein levels of MMP-2 and MMP-9 (Fig. 6B, $p<0.01$ ). Therefore, AB23A probably inhibits the invasion and migration of SK-HEP-1 cells by MMP-2 and MMP-9 proteins. Bcl-2 is an apoptosis inhibitor and Bax is a pro-apoptotic factor (Llambi and Green 2011).

To further investigate the mechanism by which $30 \mu \mathrm{mol} / \mathrm{l}$ AB23A induces cell apoptosis, RT-PCR and Western blotting were used to detect the expression of Bcl-2, Bax, Caspase-9 and Caspase-3. As shown in Figures 6A and 6B, our results
A
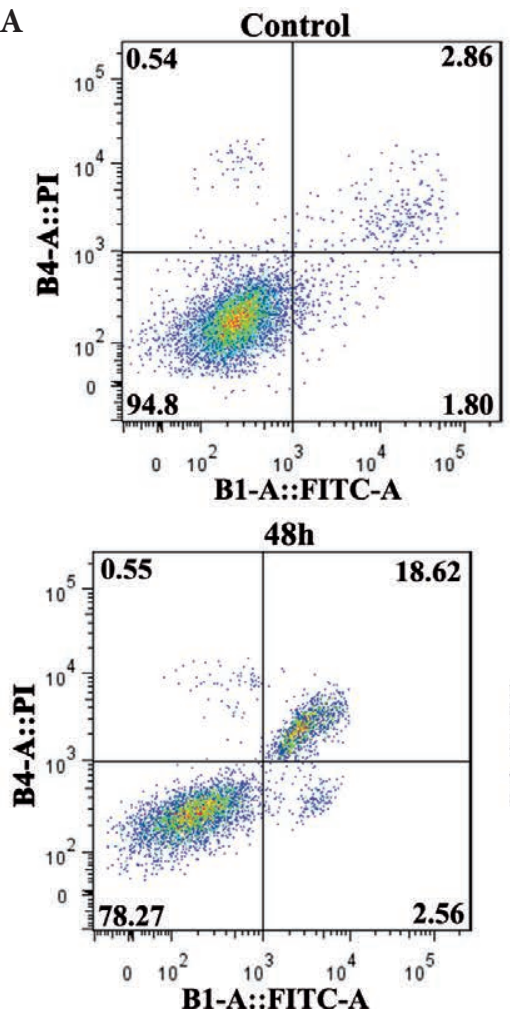

12h

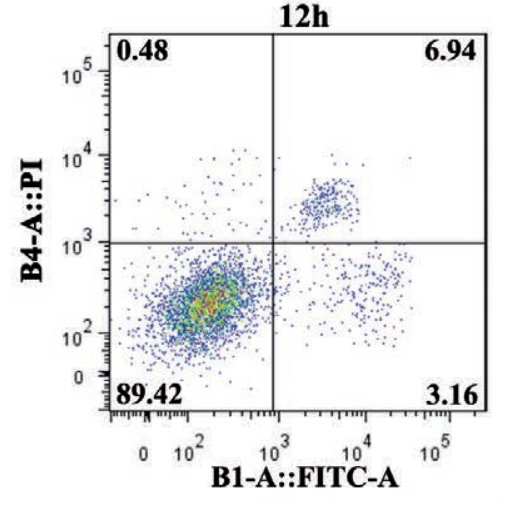

72h

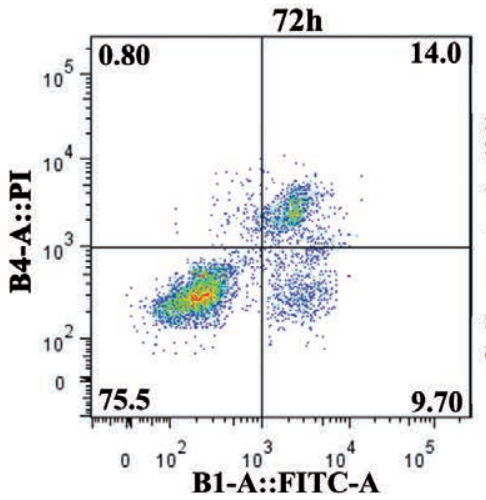

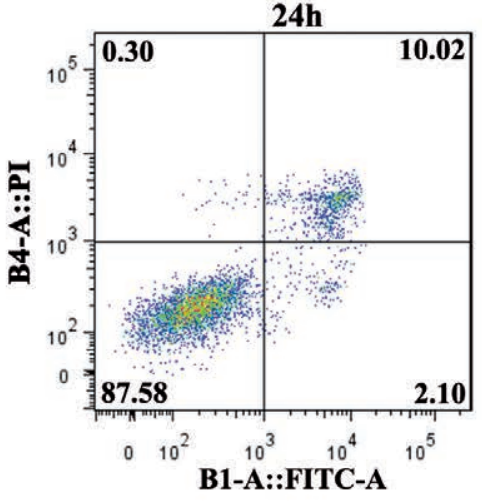

B

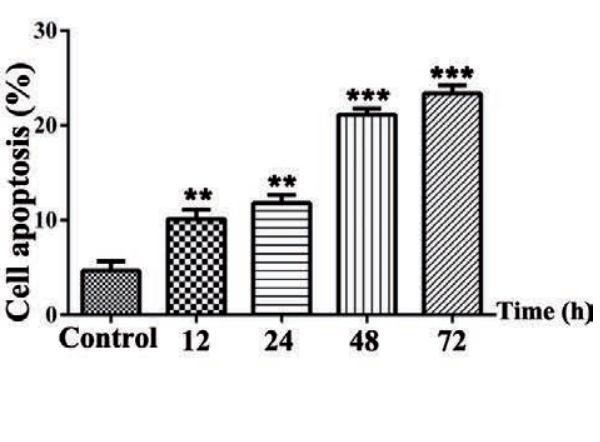

Figure 3. AB23A induces apoptosis in SK-HEP-1 cells. A. SK-HEP-1 cells were treated with AB23A (30 $\mu$ mol/l) for different times (12, 24, 48 and $72 \mathrm{~h}$ ), stained with Annexin V-FITC/PI and analyzed by flow cytometry. B. Quantification of apoptosis at different times after cells were exposed with AB23A $(30 \mu \mathrm{mol} / \mathrm{l})$. Data are mean \pm SD of three experiments. ${ }^{* *} p<0.01$ and ${ }^{* * *} p<0.001$ versus Control. 

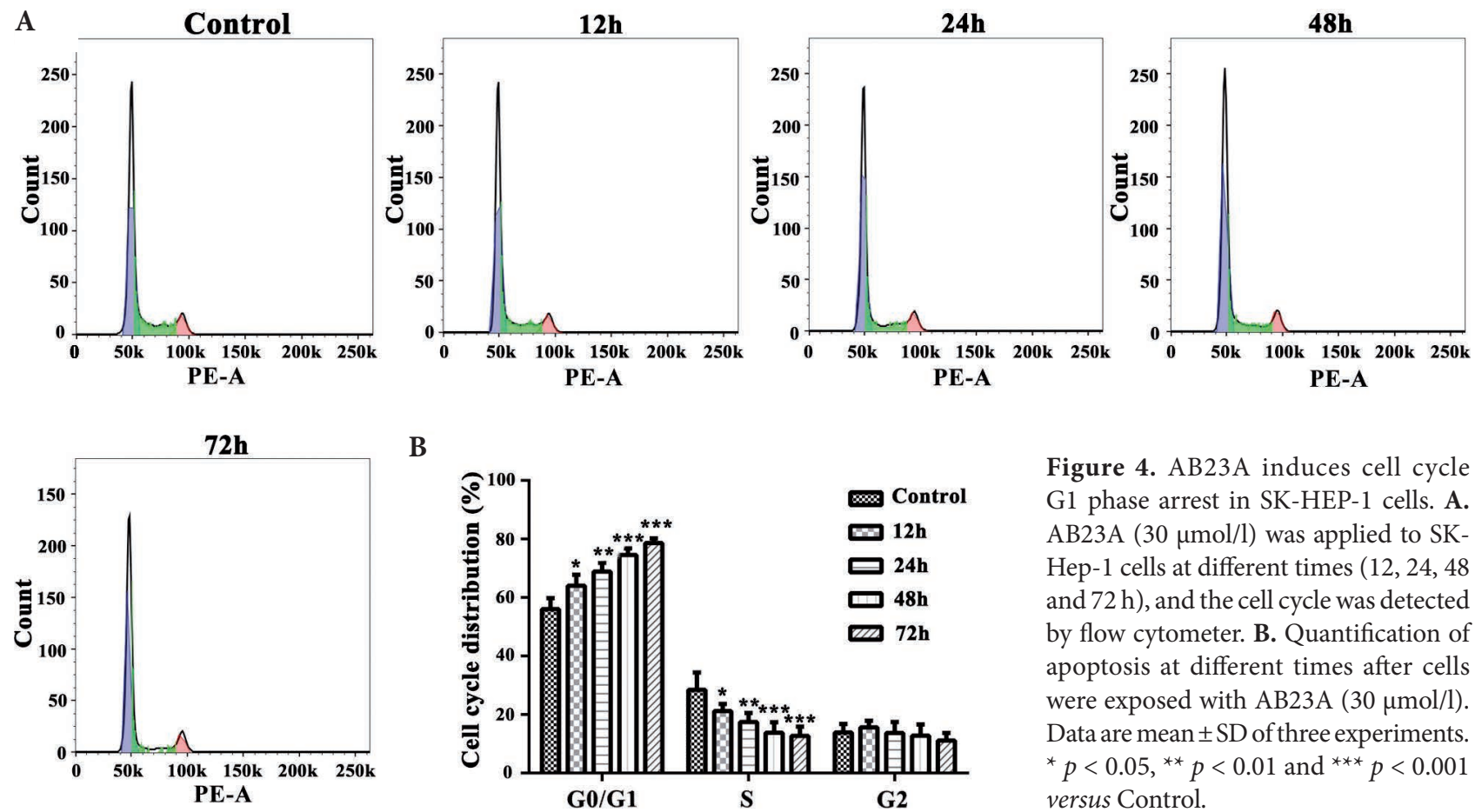

B

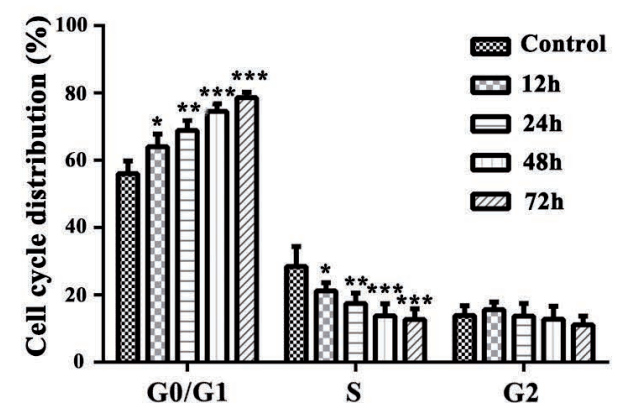

Figure 4. AB23A induces cell cycle G1 phase arrest in SK-HEP-1 cells. A. AB23A $(30 \mu \mathrm{mol} / \mathrm{l})$ was applied to SKHep- 1 cells at different times (12, 24, 48 and $72 \mathrm{~h}$ ), and the cell cycle was detected by flow cytometer. B. Quantification of apoptosis at different times after cells were exposed with AB23A $(30 \mu \mathrm{mol} / \mathrm{l})$. Data are mean \pm SD of three experiments. ${ }^{\star} p<0.05,{ }^{* *} p<0.01$ and ${ }^{* *} p<0.001$ versus Control. showed that AB23A induced cell cycle G1 arrest and cell apoptosis by up-regulating the mRNA and protein levels of Bax, Caspase-3 and Caspase-9, and down-regulating the mRNA and protein levels of Bcl-2 in SK-HEP-1 cells. Therefore, AB23A induces the apoptosis of SK-HEP-1 cells through Bcl-2, Bax and Caspase-3/9 proteins.

The PI3k-AKT signaling pathway plays an important role in the development of cancer (Polivka and Janku 2014). In addition, we found that $\mathrm{AB} 23 \mathrm{~A}$ inhibited the mRNA and protein levels of $\mathrm{p}$-PI3K/AKT compared with the control group by RT-PCR and Western blot assay (Fig. 6C). Therefore, these results suggested that AB23A suppressed cell proliferation, invasion and migration, and induced cell apoptosis by regulating the expression of PI3K/Akt signaling pathway in HCC.

AB23A suppresses tumour growth and mice body weight, and regulates related proteins expression in the SK-HEP-1 xenograft model

The tumour volume was recorded every 5 days, and the result shown in Figure 7A demonstrated that there was a dramatic decrease after AB23A treatment (Day15, $p<0.01$; Day20, $p<0.001$ ), and the body weight of $\mathrm{BALB} / \mathrm{c}$ mice in the drug group was lower than that in the control group (Fig. $7 \mathrm{~B}, p<0.01)$. Finally, we gathered the tumour tissues and determined the expression of MMP-2 and MMP-9 related to migration, and Caspase-3, Caspase-9, Bax and Bcl-2 related to cell apoptosis and cycle, using Western blotting analysis. The expression of MMP-2, MMP-9 and Bcl-2 were all reduced, whereas Caspase-3, Caspase- 9 and Bax were increased in tumor tissues in the drug group (Fig. 7C). Taken together, AB23A was demonstrated to regulate SK-HEP-1 tumorigenesis both in vitro and in vivo via regulating cell proliferation, migration and apoptosis.

\section{Discussion}

Alismatis Rhizoma was commonly used to treat many diseases, including diabetes, pyelonephtitis, inflammation and cancer (Zhang et al. 2017b). AB23A had been proved to be a natural triterpenoid with the pharmacological activity of anti-cancer (Xu et al. 2017), and it inhibited the proliferation of MDA-MB-231 cells through the induction of apoptosis (Zhang et al. 2017a).

AB23A protects against non-alcoholic steatohepatitis in mice by farnesoid X receptor activation (Meng et al. 2015). In ovarian cancer cells, AB23A induced cell apoptosis and accumulation of the sub-G1 phase, and inhibited cell migration and invasion (Zhang et al. 2016). In present study, we examined the anti-cancer effects of AB23A on SK-HEP-1 cells and explored its underlying molecule mechanism using molecular levels techniques.

Recent study has showed that AB23A induced cell apoptosis and accumulation of the G1 phase in ovarian cancer cells 
(Zhang et al. 2016). In the present study, it was discovered that AB23A arrested SK-HEP-1 cells at G1 phase and subsequently suppressed cell growth in HCC. Apoptosis is also generally believed to be the key anti-proliferative mechanism of anticancer drugs in many tumor cells types. Accumulating studies showed that many anticancer drugs induced cell apoptosis of tumor cells. We found that AB23A induced cell apoptosis of SK-HEP-1 cells. The factors of Caspase enzyme system act pivotal parts in cell apoptosis process with Caspase- 3 being one of the genes most closely associated with apoptosis (Tormanen-Napankangas et al. 2001; Thoms et al. 2007). In addition, AB23A induced cell cycle G1 arrest and cell apoptosis by up-regulating the expression of Bax, Caspase- 3 and Caspase-9, and down-regulating the protein expression of Bcl-2 in HCC cells.
Furthermore, we found that AB23A inhibited the migration and invasion of SK-HEP-1 cells. Matrix metalloproteinases (MMPs) are proteolytic enzymes that play an important role in the invasion and metastasis (Serra et al. 2014; Banday et al. 2016). AB23A suppressed the levels and activity of MMP-2 and MMP-9 compared to the control group. Therefore, AB23A inhibits the invasion and migration of HCC cells by MMP-2 and MMP-9 proteins. It was obtained that SK-HEP-1 cells were obviously inhibited by the influence of $\mathrm{AB} 23 \mathrm{~A}$ both in vitro and in vivo.

Phosphatidylinositol 3-kinase/protein kinase B (PI3K/ $\mathrm{AKT}$ ) is involved in different cellular processes from cell survival or proliferation to cell apoptosis or death (Morgan et al. 2009). Evidence showed that the inhibition of PI3K/AKT signaling pathway leads to cell apoptosis (Heras-Sandoval
$\mathbf{A}$

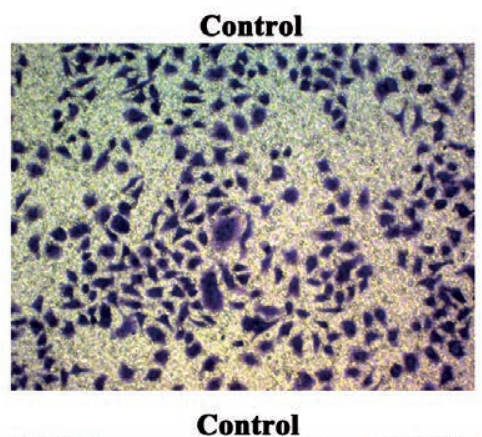

B
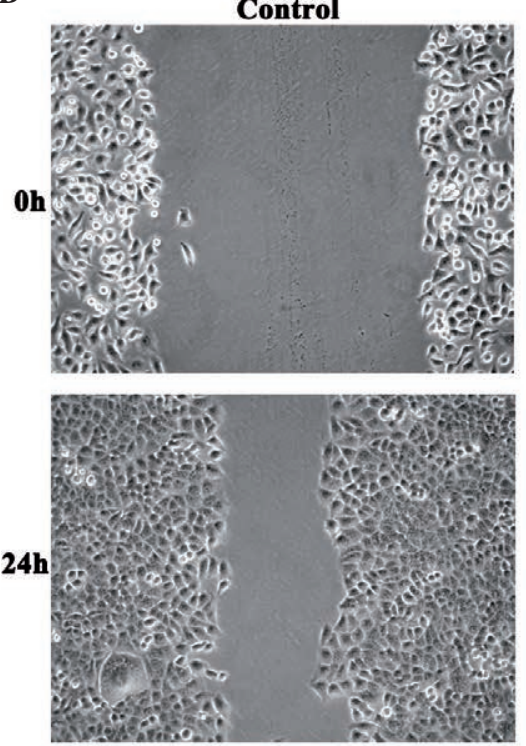

C

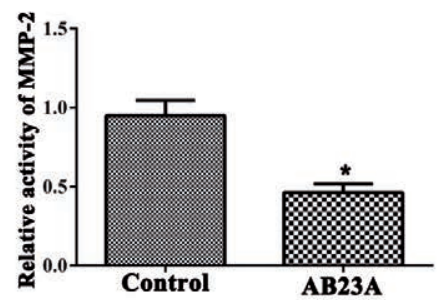

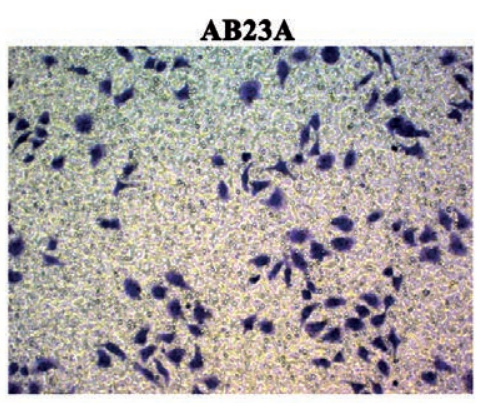

AB23A
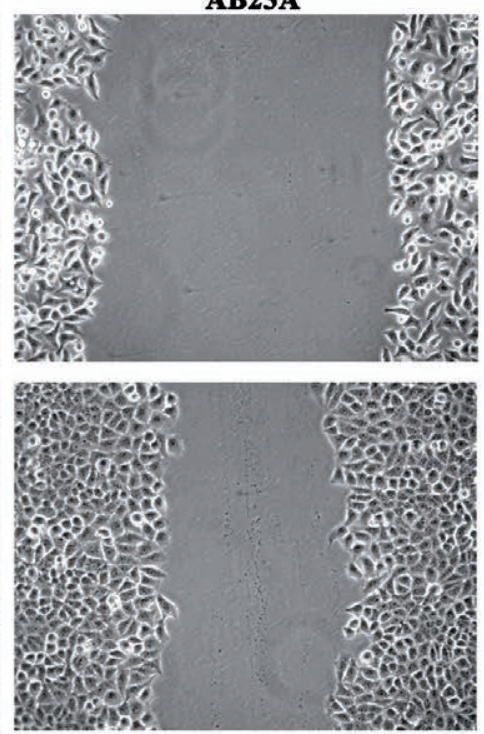

D

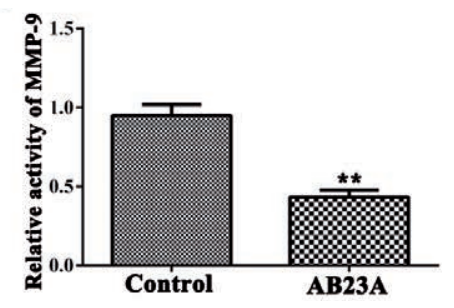

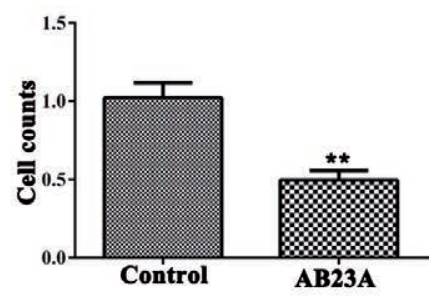

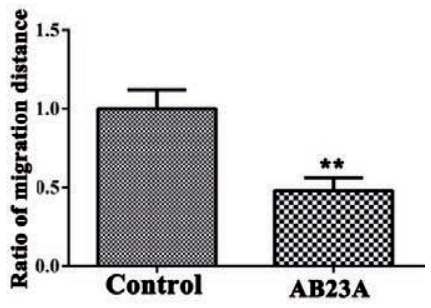

Figure 5. AB23A inhibits the invasion and migration by suppressing MMP-2 and MMP-9 protein expression in SKHEP-1 cells. A. The effect of AB23A on cell invasion by Transwell assays; the column graph displays audio-visually the results of the analysis of Transwell assays. B. The effect of AB23A $(30 \mu \mathrm{mol} / \mathrm{l})$ on cell migration at 0 and $24 \mathrm{~h}$ by scratch wound healing assays; the column graph displays audio-visually the results of the analysis of wound healing assays. C, D. The activity of MMP-2 and MMP-9 were determined using an enzyme assay. Data are mean \pm SD of three experiments. ${ }^{*} p<0.05$ and ${ }^{\star *} p<0.01$ versus Control. 
et al. 2014). Activation of PI3K can up-regulate the phosphorylation of Akt, which thereby regulates the PI3K/Akt signal pathway, leading to phosphorylate and inhibiting cell apoptosis. In present study, AB23A inhibited the protein expression of $\mathrm{p}-\mathrm{PI} 3 \mathrm{~K} / \mathrm{AKT}$ compared to the control group. What's more, AB23A suppressed the cell growth, invasion and migration, and induced cell apoptosis by regulating PI3K/Akt signaling pathway in HCC.

\section{Conclusion}

In conclusion, our results indicated that $\mathrm{AB} 23 \mathrm{~A}$, a protostane-type triterpenoid isolated from the Chinese herb Alismatis Rhizoma, possessed potent anticancer function in HCC by inhibiting cell growth, invasion and migration, and inducing cell cycle arrest and cell apoptosis. In addition, the up-regulation of Bax, Caspase-3 and Caspase-9,
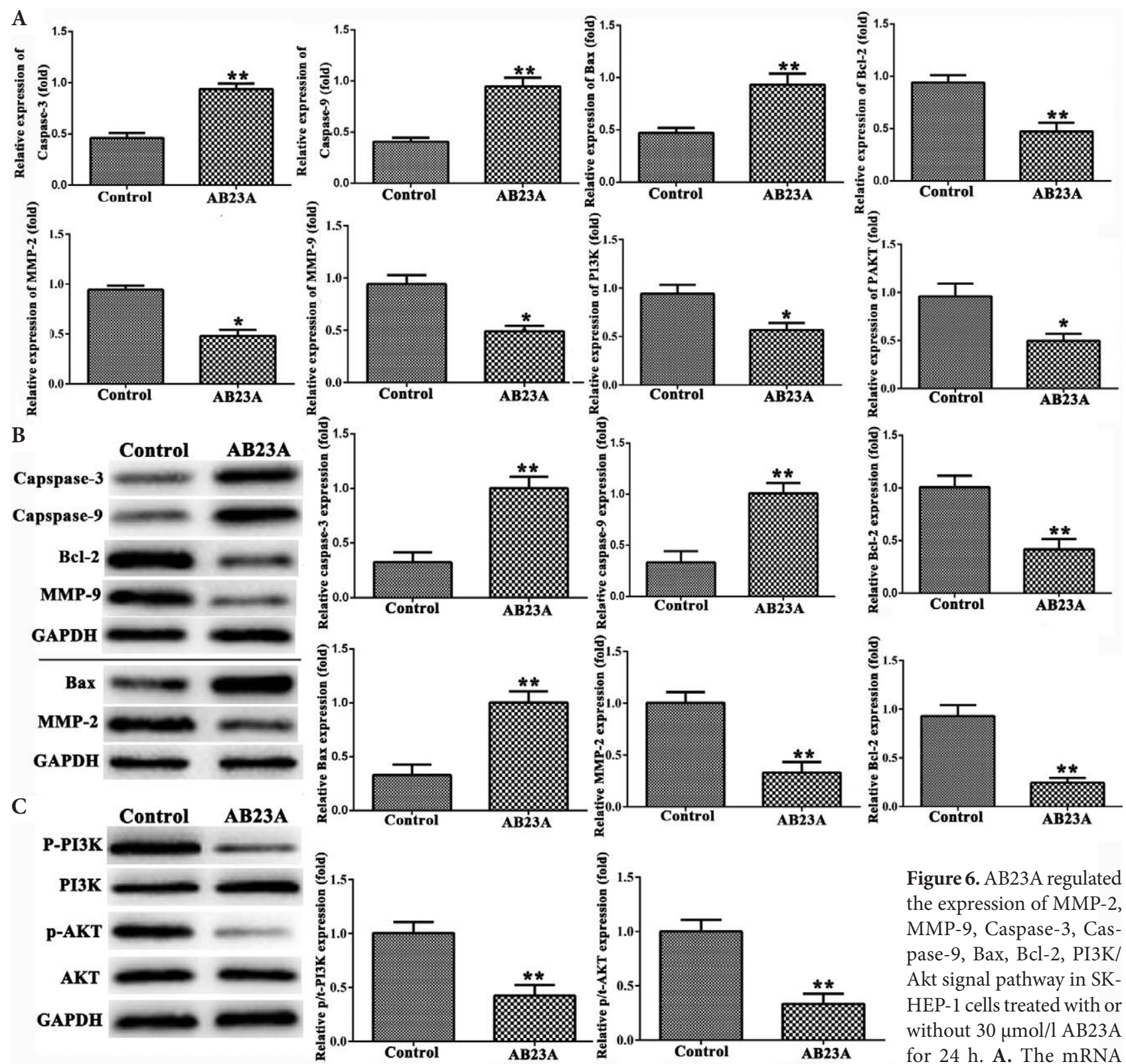

Figure 6. AB23A regulated the expression of MMP-2, MMP-9, Caspase-3, Caspase-9, Bax, Bcl-2, PI3K/ Akt signal pathway in SKHEP-1 cells treated with or without $30 \mu \mathrm{mol} / \mathrm{l} \mathrm{AB} 23 \mathrm{~A}$ for $24 \mathrm{~h}$. A. The mRNA levels of Caspase-9, Caspase-3, Bax, Bcl-2, MMP-2, MMP-9 and PI3K/Akt were determined by RT-PCR assay (also seen the values of relative mRNA expression in Table S1 of the Supplementary Material). B, C. The protein expression of Caspase-9, Caspase-3, Bax, Bcl-2, MMP-2, MMP-9 and $\mathrm{p} / \mathrm{t}-\mathrm{PI} 3 \mathrm{~K} /$ Akt were assessed using Western blotting assay. Data are mean $\pm \mathrm{SD}$ of three experiments. ${ }^{\star} p<0.05,{ }^{* *} p<0.01$ and ${ }^{* * *} p<$ 0.001 versus Control. 
A

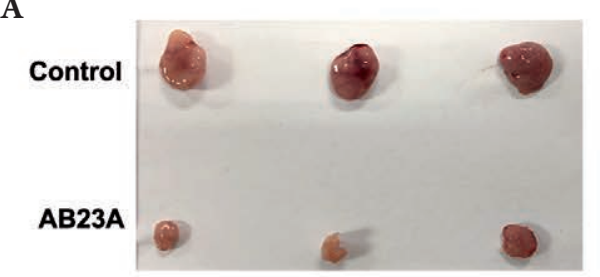

B

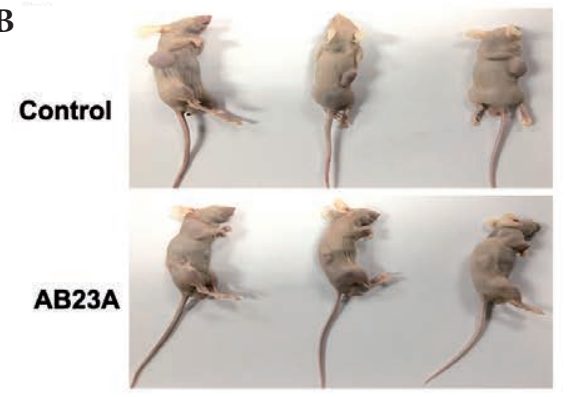

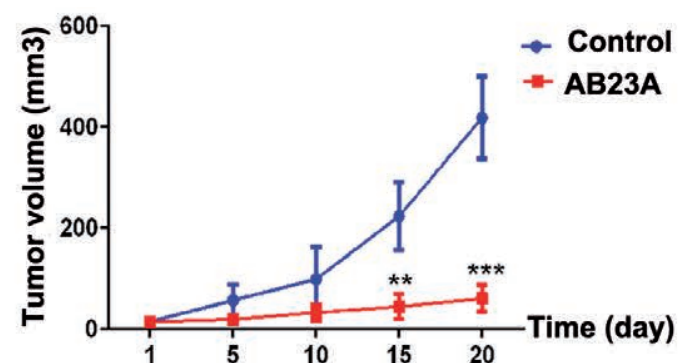

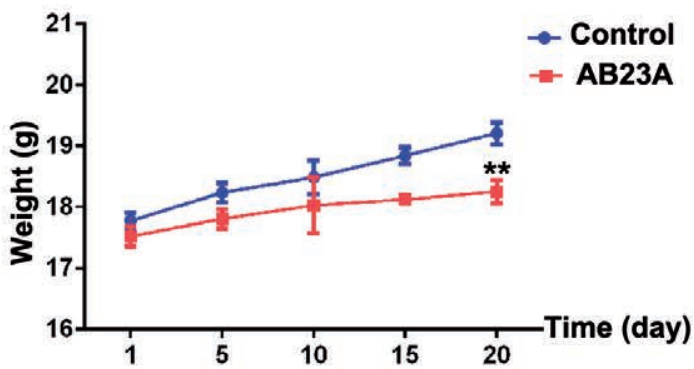

C
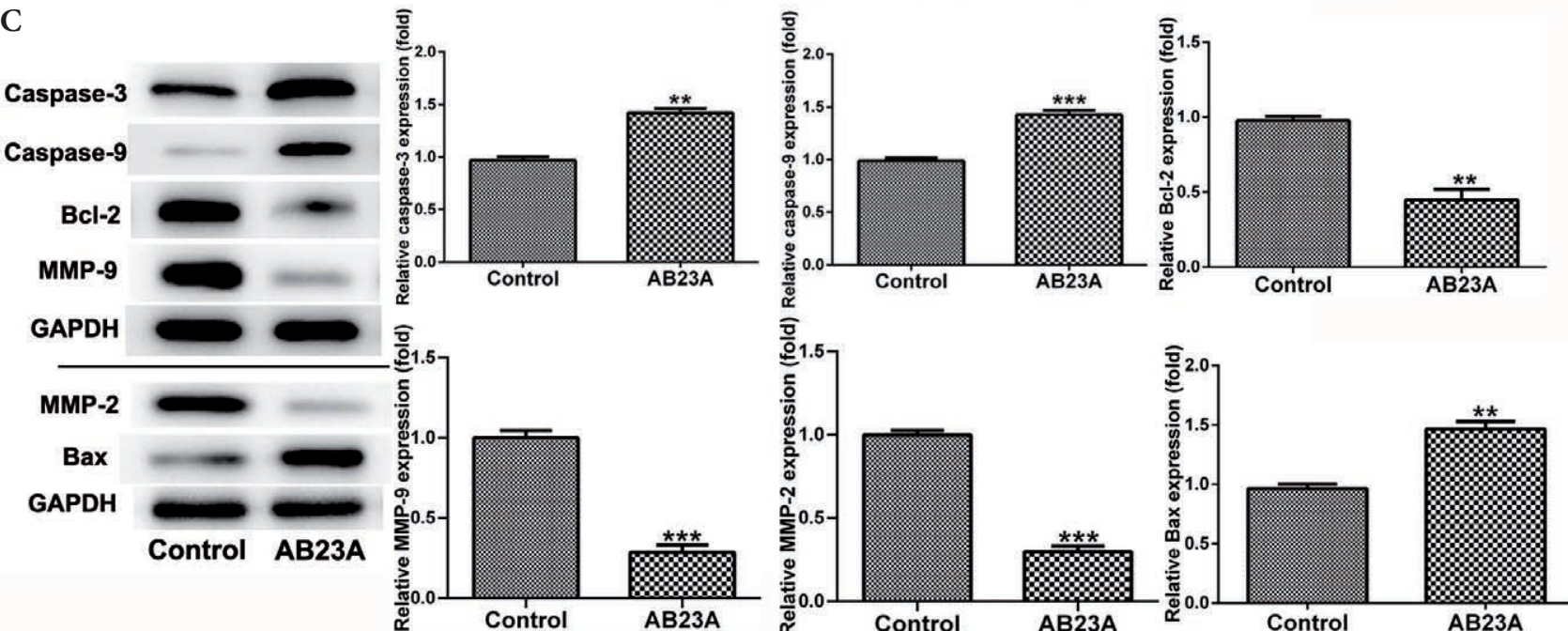

Figure 7. AB23A suppresses tumor growth and weight, and regulates related proteins expression in vivo of tumor-bearing mice. BALB/c nude mice were subcutaneously injected with SK-HEP-1 cells treated with or without $30 \mu \mathrm{mol} / \mathrm{l}$ AB23A for $24 \mathrm{~h}$. Tumour volume (A) and weight (B) were observed and analyzed every 5 days post-injection. The representative images of bearing tumors and tumor-bearing mice were shown. C. The expression of MMP-2, MMP-9, Caspase-3, Caspase-9, Bax and Bcl-2 in the tumour xenograft were detected by Western blotting (also seen the values of relative protein expression in Table S2 of the Supplementary Material). Data are mean \pm SD of three experiments. ${ }^{* *} p<0.01$ and ${ }^{* * *} p<0.001$ versus Control

down-regulation of Bcl-2, MMP-2, MMP-9 both in vitro and in vivo, and inhibition of PI3K/Akt may account for the molecular mechanism for pharmacological effects of $\mathrm{AB} 23 \mathrm{~A}$. AB23A may be a promising monomer molecule of traditional Chinese medicine, with high clinical application value in the treatment of human hepatocellular carcinoma.

Acknowledgment. Not applicable.
Conflict of interests. The authors declare that they have no competing interests.

\section{References}

Banday MZ, Sameer AS, Mir AH, Mokhdomi TA, Chowdri NA, Haq $\mathrm{E}$ (2016): Matrix metalloproteinase (MMP) -2, -7 and -9 promoter polymorphisms in colorectal cancer in ethnic Kashmiri population - A case-control study and a mini review. Gene 589, 81-89 
https://doi.org/10.1016/j.gene.2016.05.028

Best J, Schotten C, Theysohn JM, Wetter A, Muller S, Radunz S, Schulze M, Canbay A, Dechene A, Gerken G (2017): Novel implications in the treatment of hepatocellular carcinoma. Ann. Gastroenterol. 30, 23-32

Heras-Sandoval D, Perez-Rojas JM, Hernandez-Damian J, PedrazaChaverri J (2014): The role of PI3K/AKT/mTOR pathway in the modulation of autophagy and the clearance of protein aggregates in neurodegeneration. Cell Signal. 26, 2694-2701 https://doi.org/10.1016/j.cellsig.2014.08.019

Hu Y, Wang S, Wu X, Zhang J, Chen R, Chen M, Wang Y (2013): Chinese herbal medicine-derived compounds for cancer therapy: a focus on hepatocellular carcinoma. J. Ethnopharmacol. 149, 601-612 https://doi.org/10.1016/j.jep.2013.07.030

Jemal A, Bray F, Center MM, Ferlay J, Ward E, Forman D (2011): Global cancer statistics. CA Cancer J. Clin. 61, 69-90 https://doi.org/10.3322/caac.20107

Jin HG, Jin Q, Ryun Kim A, Choi H, Lee JH, Kim YS, Lee DG, Woo ER (2012): A new triterpenoid from Alisma orientale and their antibacterial effect. Arch. Pharm. Res. 35, 1919-1926 https://doi.org/10.1007/s12272-012-1108-5

Llambi F, Green DR (2011): Apoptosis and oncogenesis: give and take in the BCL-2 family. Curr. Opin. Genet. Dev. 21, 12-20 https://doi.org/10.1016/j.gde.2010.12.001

Meng Q, Chen X, Wang C, Liu Q, Sun H, Sun P, Huo X, Liu Z, Liu K (2015): Protective effects of alisol B 23-acetate from edible botanical Rhizoma alismatis against carbon tetrachlorideinduced hepatotoxicity in mice. Food \& Function 6, 1241-1250 https://doi.org/10.1039/C5FO00082C

Morgan TM, Koreckij TD, Corey E (2009): Targeted therapy for advanced prostate cancer: inhibition of the PI3K/Akt/mTOR pathway. Current Cancer Drug Targets 9, 237-249 https://doi.org/10.2174/156800909787580999

Polivka J, Jr, Janku F (2014): Molecular targets for cancer therapy in the PI3K/AKT/mTOR pathway. Pharmacology \& Therapeutics 14, 164-175 https://doi.org/10.1016/j.pharmthera.2013.12.004

Serra R, Grande R, Gallelli L, Rende P, Scarcello E, Buffone G, Calio FG, Gasbarro V, Amato B, de Franciscis S (2014): Carotid body paragangliomas and matrix metalloproteinases. Ann. Vasc. Surg. 28, 1665-1670 https://doi.org/10.1016/j.avsg.2014.03.022

Thoms HC, Dunlop MG, Stark LA (2007): p38-mediated inactivation of cyclin D1/cyclin-dependent kinase 4 stimulates nucleolar translocation of RelA and apoptosis in colorectal cancer cells. Cancer Res. 67, 1660-1669 https://doi.org/10.1158/0008-5472.CAN-06-1038

Tormanen-Napankangas U, Soini Y, Kahlos K, Kinnula V, Paakko P (2001): Expression of Caspases-3, -6 and -8 and their relation to apoptosis in non-small cell lung carcinoma. Int. J. Cancer 93, 192-198 https://doi.org/10.1002/ijc.1315

Torre LA, Bray F, Siegel RL, Ferlay J, Lortet-Tieulent J, Jemal A (2015): Global cancer statistics, 2012. CA Cancer J. Clin. 65, $87-108$ https://doi.org/10.3322/caac.21262

Wang C, Feng L, Ma L, Chen H, Tan X, Hou X, Song J, Cui L, Liu D, Chen J, et al. (2017): Alisol A 24-acetate and alisol B 23-acetate induced autophagy mediates apoptosis and nephrotoxicity in human renal proximal tubular cells. Front. Pharmacol. 8, 172 https://doi.org/10.3389/fphar.2017.00172

Wang H (2013): Preventive effects of ophiopogon-polysaccharide on apiponectin in gestational diabetes mellitus rat. Asian Pacific Journal of Tropical Medicine 6, 296-299 https://doi.org/10.1016/S1995-7645(13)60059-0

Wu J, Yang W, Pan H, Yao S, Wu W, Guo D (2018): Geographic impact evaluation of the quality of Alismatis Rhizoma by untargeted metabolomics and quantitative assay. Journal of Separation Science 41, 839-846 https://doi.org/10.1002/jssc.201700902

Xu W, Li X, Lin N, Zhang X, Huang X, Wu T, Tai Y, Chen S, Wu C, Huang M, Wu S (2017): Pharmacokinetics and tissue distribution of five major triterpenoids after oral administration of Rhizoma Alismatis extract to rats using ultra high-performance liquid chromatography-tandem mass spectrometry. J. Pharm. Biomed. Anal. 146, 314-323 https://doi.org/10.1016/j.jpba.2017.09.009

Zhang A, Sheng Y, Zou M (2017a): Antiproliferative activity of Alisol B in MDA-MB-231 cells is mediated by apoptosis, dysregulation of mitochondrial functions, cell cycle arrest and generation of reactive oxygen species. Biomed. Pharmacother. 87, $110-117$ https://doi.org/10.1016/j.biopha.2016.12.088

Zhang LL, Xu YL, Tang ZH, Xu XH, Chen X, Li T, Ding CY, Huang MQ, Chen XP, Wang YT, Yuan XF, Lu JJ (2016): Effects of alisol B 23-acetate on ovarian cancer cells: G1 phase cell cycle arrest, apoptosis, migration and invasion inhibition. Phytomedicine 23, 800-809 https://doi.org/10.1016/j.phymed.2016.04.003

Zhang X, Li XY, Lin N, Zhao WL, Huang XQ, Chen Y, Huang MQ, $\mathrm{Xu}$ W, Wu SS (2017b): Diuretic activity of compatible triterpene components of Alismatis rhizoma. Molecules 22, e1459 https://doi.org/10.3390/molecules22091459

Zhao K, Zhang Y, Kang L, Song Y, Wang K, Li S, Wu X, Hua W, Shao Z, Yang S, Yang C (2017): Epigenetic silencing of miRNA-143 regulates apoptosis by targeting BCL2 in human intervertebral disc degeneration. Gene 628, 259-266 https://doi.org/10.1016/j.gene.2017.07.043

Received: September 16, 2019

Final version accepted: January 21, 2020 


\section{Supplementary Material}

\section{The effects of Alisol B 23-acetate in hepatocellular carcinoma via inducing cell apoptosis and inhibiting cell migration and invasion}

Ling $\mathrm{Li}^{1}$, Jingjun Cheng ${ }^{2}$, Dedong Zhu ${ }^{1}$, Xiaojun $\mathrm{Shi}^{1}$, Yongning $\mathrm{Wei}^{1}$, Sihan $\mathrm{Chen}^{1}$, Zhe Wang ${ }^{1}$ and Denggao Yuan ${ }^{1}$

${ }^{1}$ Department of Liver Oncology, HwaMei Hospital, University of Chinese Academy of Sciences, Jiangbei District, Ningbo, Zhejiang, China

${ }^{2}$ Department of Internal Medicine, Huangjiahu Hospital Affiliated to Hubei University of Traditional Chinese medicine, Hongshan District, Wuhan, Hubei, China

Table S1. The values of relative mRNA expression of Caspase-3, Caspase-9, Bax, Bcl-2, MMP-2, MMP-9, PI3K and AKT in SK-HEP-1 cells (mean \pm standard deviation)

\begin{tabular}{lcccccccc}
\hline Group & Caspase-3 & Caspase-9 & Bax & Bcl-2 & MMP-2 & MMP-9 & PI3K & AKT \\
\hline Control & $0.46 \pm 0.05$ & $0.41 \pm 0.04$ & $0.47 \pm 0.05$ & $0.94 \pm 0.07$ & $0.89 \pm 0.08$ & $0.94 \pm 0.08$ & $0.94 \pm 0.09$ & $0.96 \pm 0.13$ \\
Drug & $0.94 \pm 0.06$ & $0.95 \pm 0.09$ & $0.93 \pm 0.11$ & $0.47 \pm 0.09$ & $0.47 \pm 0.06$ & $0.49 \pm 0.05$ & $0.57 \pm 0.07$ & $0.49 \pm 0.07$ \\
\hline
\end{tabular}

Table S2. The values of relative protein expression of Caspase-3, Caspase-9, Bax, Bcl-2, MMP-2 and MMP9 in tumour tissues (mean \pm standard deviation)

\begin{tabular}{lcccccc}
\hline Group & Caspase-3 & Caspase-9 & Bax & Bcl-2 & MMP-2 & MMP-9 \\
\hline Control & $0.96 \pm 0.06$ & $0.98 \pm 0.05$ & $0.96 \pm 0.06$ & $0.98 \pm 0.05$ & $0.99 \pm 0.03$ & $1.00 \pm 0.05$ \\
Drug & $1.42 \pm 0.07$ & $1.43 \pm 0.07$ & $1.47 \pm 0.11$ & $0.45 \pm 0.12$ & $0.30 \pm 0.03$ & $0.29 \pm 0.05$ \\
\hline
\end{tabular}

